\title{
Nicotine, aerosol particles, carbonyls and volatile organic compounds in tobacco- and menthol-flavored e-cigarettes
}

\author{
Mi-Sun Lee ${ }^{1}$, Ryan F. LeBouf ${ }^{2}$, Youn-Suk Son ${ }^{3}$, Petros Koutrakis ${ }^{4}$ and David C. Christiani ${ }^{1,5^{*}}$
}

\begin{abstract}
Background: We aimed to assess the content of electronic cigarette (EC) emissions for five groups of potentially toxic compounds that are known to be present in tobacco smoke: nicotine, particles, carbonyls, volatile organic compounds (VOCs), and trace elements by flavor and puffing time.

Methods: We used ECs containing a common nicotine strength (1.8\%) and the most popular flavors, tobacco and menthol. An automatic multiple smoking machine was used to generate EC aerosols under controlled conditions. Using a dilution chamber, we targeted nicotine concentrations similar to that of exposure in a general indoor environment. The selected toxic compounds were extracted from EC aerosols into a solid or liquid phase and analyzed with chromatographic and spectroscopic methods.

Results: We found that EC aerosols contained toxic compounds including nicotine, fine and nanoparticles, carbonyls, and some toxic VOCs such as benzene and toluene. Higher mass and number concentrations of aerosol particles were generated from tobacco-flavored ECs than from menthol-flavored ECs.

Conclusion: We found that diluted machine-generated EC aerosols contain some pollutants. These findings are limited by the small number of ECs tested and the conditions of testing. More comprehensive research on EC exposure extending to more brands and flavor compounds is warranted.
\end{abstract}

Keywords: Nicotine, Particles, Carbonyls, VOCs in e-cigarette emissions

\section{Background}

Electronic cigarettes (referred to as 'ECs' hereafter) deliver nicotine with flavorings and other additives via inhalation without combustion. They are marketed as an alternative to conventional cigarettes [1]. In August 2016, a new U.S. Food and Drug Administration (FDA) regulation was promulgated to regulate all tobacco products including ECs, and the sale of these products was banned to people under age 18 years (http://www.fda.gov/TobaccoProducts/Label ing/RulesRegulationsGuidance/ucm394909.htm).

Although the FDA has not yet developed standards for testing or for acceptable emissions, current evidence on the emission from EC smoking raises health concerns.

\footnotetext{
* Correspondence: dchris@hsph.harvard.edu

'Environmental and Occupational Medicine and Epidemiology Program, Department of Environmental Health, Harvard T. H. Chan School of Public Health, 665 Huntington Ave, Building I Room 1401, Boston MA 02115, USA ${ }^{5}$ Massachusetts General Hospital/Harvard Medical School, Boston, MA, USA

Full list of author information is available at the end of the article
}

Wide ranges in the levels of chemical substances, such as nicotine, tobacco-specific nitrosamines, aldehydes, metals, volatile organic compounds (VOCs), phenolic compounds, polycyclic aromatic hydrocarbons, flavors, aerosol particles, and solvent carriers have been reported in various EC matrices, including refill solutions, cartridges, aerosols and environmental emissions (reviewed in $[2,3])$. Particle number concentration was found to be similar or higher in EC emissions than in conventional tobacco cigarette smoke [4]. VOCs (e.g., benzene classified as a known human carcinogen for all routes of exposure by EPA) and carbonyl compounds (e.g., formaldehyde, acetaldehyde, and acrolein) were at lower concentrations in EC emissions than in conventional cigarettes [5-7]. Heavy metal (e.g., lead and nickel) concentrations in EC emissions were equal to or higher than concentrations in conventional cigarettes [8]. 
However, current evidence on emission profiles is of limited use for risk assessment in the US population. Many studies have analyzed chemicals in refill solutions and cartridges rather than in EC emissions and can only infer possible emission levels [2]. Cheng [2] has stated that there is a "strong need for evaluation of products currently on the US market", indicating that there is little information available for US products, especially regarding their flavor-based emission profiles.

Therefore, our study aimed to assess the content of emissions for ECs with flavors (tobacco and menthol) that dominated the U.S. market $(95 \%>)$ in 2013 [9]. We considered whether flavor and puffing time affect the emission of five groups of chemical compounds present in tobacco smoke: nicotine, fine particle fractions, including nanoparticles or ultrafine particles $\left(\mathrm{PM}_{0.1}\right.$ or UFPs, particulate matter of aerodynamic diameter less than $100 \mathrm{~nm})$ and fine particles $\left(\mathrm{PM}_{2.5}\right.$, particulate matter of aerodynamic diameter less than $2.5 \mu \mathrm{m}$ ), particle number concentration ( $\mathrm{PNC}$, particle size range from 0.02 to $1 \mu \mathrm{m})$, carbonyls, VOCs, and trace elements.

\section{Methods}

\section{EC aerosol generation system}

EC aerosol generation and sampling was performed in the Environmental Chemistry Laboratory at the Harvard T.H. Chan School of Public Health where thermo-hygrometric conditions were continuously monitored. We used two dominant flavors, tobacco and menthol, of the EC V2 brand (VMR Products, LLC), a popular U.S. brand, containing a nicotine strength of $1.8 \%$, which is a popular "strength" consumed by experienced EC users [10] and is close to the maximum level set by the European Commission regulatory proposal [11] (http://www.europarl.euro pa.eu/pdfs/news/expert/infopress/20131216IPR31001/2013 1216IPR31001_en.pdf). The EC devices used in this study were rechargeable "cigalike" devices consisting of a cartomizer, which combines a disposable cartridge (which holds a liquid solution) and a built-in atomizer, and a rechargeable battery with a glowing red light-emitting diode (LED) tip on the end that lights up with each puff and serves as an indicator of use. This device has the same components as many EC devices. The tip of the cartridge served as the EC's mouthpiece. The liquid in the cartridge was heated by a battery and turned into a vapor by an atomizer. The EC aerosol generation system consisted of a smoking machine, mixing chamber, dilution chamber, suction controller and two zero air systems, as shown in Fig. 1. A dilution chamber was used to generate stable concentrations of machine-generated aerosols with nicotine levels similar to those in a general indoor environment. As targeted, the concentrations of nicotine generated from our smoking machine were within the range of previous studies [12-15]. The automatic multiple smoking machine
(Modified TE-2 system, Teaque Enterprises, CA, USA) was used to generate EC aerosols. This is a multiple port linear piston-like smoking machine with adjustable and very wide-ranging puffing regimes. The determination of the characteristics of machine-generated EC emissions was done under controlled conditions of temperature, relative humidity and air exchange rate [16]. The EC aerosol generated from the smoking machine was entered into a mixing chamber at a flow rate of $1.3 \mathrm{~L} / \mathrm{min}$ and mixed with pure air through zero air system \#1 (10 L/min). The volume and air exchange rate of the chamber was $442.5 \mathrm{~L}$ $(0.762 \times 0.762 \times 0.762 \mathrm{~m})$ and $1.53 \mathrm{~h}^{-1}$, respectively. The mixed EC aerosol at $4.3 \mathrm{~L} / \mathrm{min}$ was entered into a dilution chamber to adjust for concentrations of airborne markers, such as $\mathrm{PM}_{2.5}$. At this time, additional pure air $(81 \mathrm{~L} / \mathrm{min})$ generated by zero air system \#2 was supplied to the dilution chamber to reduce the EC-emitted aerosol concentration. Consequently, the total dilution ratio of the system was 1:172 calculated by multiplying the dilution factors of the mixing (8.69) and dilution (19.8) chambers. Experiments on mixing patterns and equilibrium times of EC aerosols in the system were carried out, and it was found that EC aerosol levels in the system were consistent after 40 min of smoking machine operation to allow for equilibrium. To improve reliability of the experimental results, the system was purged with pure air. The EC aerosol was collected and analyzed using various instruments to evaluate the effect of flavor and puffing time on the aerosol characteristics. During the experimental period, the relative humidity and temperature inside the chamber were controlled at $18.8 \pm 6.7 \%$ and $34.4 \pm 0.9{ }^{\circ} \mathrm{C}$, respectively. All experiments were carried out using a smoking machine with two ECs at different puff rate(s), 1 puff and 2 puffs per min, and each experiment was repeated.

\section{Analysis of EC aerosols Nicotine}

Nicotine emitted from ECs was collected by XAD-7 sorption tubes (SKC, Inc., Eighty Four, PA, USA) at a flow rate of $1 \mathrm{~L} / \mathrm{min}$ for $60 \mathrm{~min}$. The tubes were desorbed completely using $2.0 \mathrm{~mL}$ of 2-propanol. The nicotine concentrations were measured by a 7890A gas chromatograph (Agilent Technologies, Santa Clara, CA, USA) equipped with a 5975C mass selective detector (Enthalpy Analytical, Inc., NC, USA). A Second Source sample (Nicotine SS) was analyzed along with the samples as a Laboratory Control Sample (LCS). The recovery was $108 \%$.

$P M_{2.5}$. The real-time mass concentration of $\mathrm{PM}_{2.5}$ was measured using the SidePak ${ }^{\mathrm{TM}}$ light-scattering integrating nephelometer (Model AM510, TSI, Inc., MN, USA). The one-hour (h) limit of detection (LOD) of the SidePak is estimated to be $3 \mu \mathrm{g} / \mathrm{m}^{3}$. Since the SidePak generally overestimates $\mathrm{PM}_{2.5}$ concentrations $[17,18]$, SidePak 


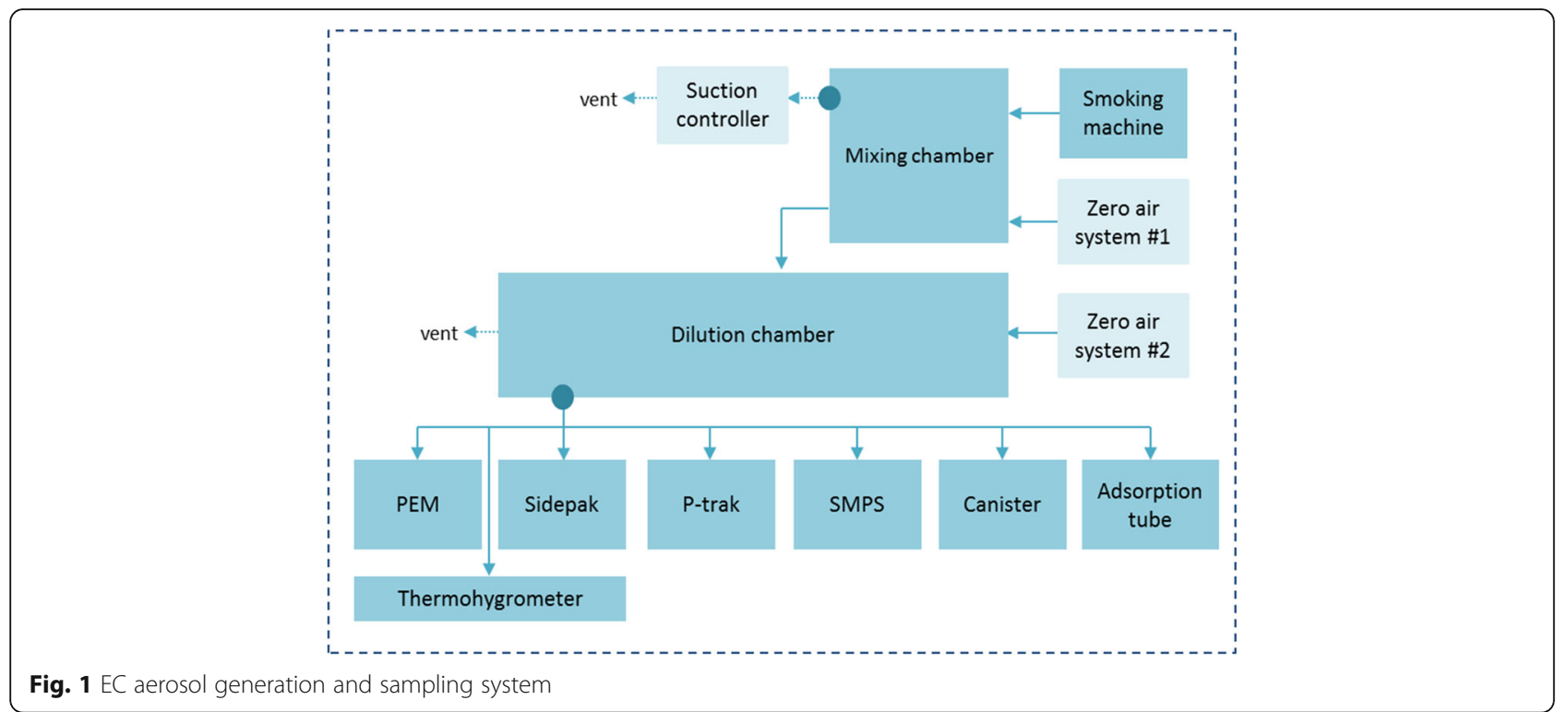

measurements were calibrated using integrated $\mathrm{PM}_{2.5}$ concentrations obtained by using a co-located Personal Exposure Monitor (PEM), which is a small inertial impactor designed specifically for personal monitoring [19]. The flow rates of all PEMs were $9 \mathrm{~L} / \mathrm{min}$. PEMs collected $\mathrm{PM}_{2.5}$ on $37-\mathrm{mm}$ Teflon filters placed downstream of a size-selective inlet that uses a greased impaction plate. Teflon filters were weighed on an electronic microbalance (Cahn Model C-31, Cahn Instruments, Madison, WI) in duplicate before and after sample collection. Filters were equilibrated in a controlled temperature $\left(71 \pm 3{ }^{\circ} \mathrm{F}\right)$ and relative humidity $(40 \pm 5 \%)$ room, both before and after sampling. To eliminate the effects of static charge, the Teflon filters were passed over $\mathrm{Po}_{210}$ sources (alpha rays) prior to each weighing. The integrated PEM $\mathrm{PM}_{2.5}$ mass concentration is the net mass collected on the filter $(\mu \mathrm{g})$ divided by the sample volume of air $\left(\mathrm{m}^{3}\right)$, based on measured flow and duration.

We calculated the calibration factor (CF) using the average value measured by SidePak divided by the PEM concentration (Eq. 1):

$$
C F=\frac{S i d e P a k_{\text {average }}}{\text { Integrated PEM Concentration }}
$$

To determine the calibration-adjusted SidePak value for each 10-s measurement, we divided the measured value by the $C F$.

\section{Particle number concentration (PNC) and Nanoparticles}

The PNC was analyzed using the P-Trak ${ }^{\bullet}$ Ultrafine Particle Counter (TSI model 8525, TSI Inc., Shoreview, USA). The sampling flow rate and interval of P-Trak were $0.1 \mathrm{~L} / \mathrm{min}$ and $10 \mathrm{~s}$, respectively. Nanoparticle masses and number concentrations were measured over consecutive 5-min internals using the TSI Model 3936 Scanning Mobility Particle Sizer (SMPS) system consisting of the TSI Electrostatic Classifier (Model 3080) and TSI Long Differential Mobility Analyzer (Model 3081) equipped with a water-based Condensation Particle Counter (CPC, Model 3785). The sampling flow rate of the SMPS was $0.3 \mathrm{~L} / \mathrm{min}$ and the range of measurement was 10 to $1000 \mathrm{~nm}$. We assumed a particle density of $1.2 \mathrm{~g} / \mathrm{cc}$.

\section{Volatile organic compounds (VOCs) and Carbonyls}

VOCs and carbonyls were analyzed using a draft $\mathrm{Na}$ tional Institute for Occupational Safety and Health (NIOSH) canister method [20] that detects the following compounds: acetaldehyde, acetone, ethanol, acetonitrile, isopropyl alcohol, benzene, toluene, methylene chloride, 2,3-butanedione, n-hexane, chloroform, 2,3pentanedione, methyl methacrylate, 2,3-hexanedione, ethylbenzene, m,p-xylene, styrene, o-xylene, alphapinene, and d-limonene. Potentially toxic carbonyls such as acetaldehyde can form when e-liquids are heated to high temperature [5]. Acetaldehyde is classified as possibly carcinogenic to humans (Group 2B) by the International Agency for Research on Cancer (IARC) [21] and is the most abundant carcinogen in tobacco smoke. Benzene is classified as carcinogenic to humans (Group 1) by IARC [22]. Fused-silica lined canisters (6 L, Entech Instruments, Simi Valley, CA) were used to collect VOCs for $60 \mathrm{~min}$. Canisters were shipped to the NIOSH-Morgantown Organics Laboratory for analysis after pressurization with UHP nitrogen. A canister autosampler/preconcentrator (7016D/ 7200, Entech Instruments) coupled with a GCMS 
system (6890/5975, Agilent Technologies) was used to concentrate a $250 \mathrm{~mL}$ sample. Internal standards, bromochloromethane, 1,4-difluorobenzene, and chlorobenzened5, were used to quantify target analytes based on response factors.

\section{Trace elements}

An energy dispersive X-ray fluorescence (EDXRF) spectrometer was used to determine the concentrations of 48 trace elements in a range of atomic numbers from 11 $(\mathrm{Na})$ to $82(\mathrm{~Pb})$, including $\mathrm{Ag}, \mathrm{Al}, \mathrm{As}, \mathrm{Au}, \mathrm{Ba}, \mathrm{Br}, \mathrm{Ca}, \mathrm{Cd}$, $\mathrm{Ce}, \mathrm{Cl}, \mathrm{Co}, \mathrm{Cr}, \mathrm{Cs}, \mathrm{Cu}, \mathrm{Eu}, \mathrm{Fe}, \mathrm{Ga}, \mathrm{Ge}, \mathrm{Hg}, \mathrm{K}, \mathrm{La}, \mathrm{In}, \mathrm{Mg}$, $\mathrm{Mn}, \mathrm{Mo}, \mathrm{Na}, \mathrm{Nb}, \mathrm{Ni}, \mathrm{P}, \mathrm{Pb}, \mathrm{Pd}, \mathrm{Rb}, \mathrm{S}, \mathrm{Sb}, \mathrm{Sc}, \mathrm{Se}, \mathrm{Si}, \mathrm{Sm}$, $\mathrm{Sn}, \mathrm{Sr}, \mathrm{Tb}, \mathrm{Ti}, \mathrm{Tl}, \mathrm{V}, \mathrm{W}, \mathrm{Y}, \mathrm{Zn}$, and $\mathrm{Zr}$. To do this, we analyzed the characteristics of the Teflon filters used during PEM sampling. Elemental analysis was conducted using an Epsilon 5 EDXRF spectrometer (PANalytical, Almelo, The Netherlands) which utilizes secondary excitation from 10 secondary selectable targets [23]. The spectrometer employs a $600 \mathrm{~W}$ dual (scandium/ tungsten, Sc/W) anode X-ray tube, a $100 \mathrm{kV}$ generator, and a solid-state germanium (Ge) detector. A total of 49 MicroMatter XRF calibration standard polycarbonate films (Micromatter Co., Vancouver, Canada) were used for calibration of 48 elements. We also used the U. S. National Institute of Standards and Technology (NIST) standard reference material (SRM) 2783 for quality control of the analytical procedure.

\section{Statistical analysis}

All data are presented as the mean \pm standard deviation (SD) levels of selected compounds in EC emissions. The difference in EC emission levels between groups (e.g., menthol vs. tobacco flavor, 1 puff vs. 2 puffs) were tested using Student's $t$-test. In addition, linear regressions were applied to estimate percent changes as $\left(10^{\beta}-1\right) \times 100 \%$, where $\beta$ is the estimated regression coefficient, and the corresponding $95 \%$ CIs for the association between aerosol particle concentrations and type of flavor, adjusting for puffing time. All analyses were performed using SAS (version 9.4; SAS Institute Inc., Cary, NC, USA).

\section{Results}

The content of EC emissions for chemical compounds by flavor and puffing time are presented in Table 1 .

\section{Nicotine}

Nicotine was identified in all tested EC emissions. The mean concentration of nicotine was $3.13 \mu \mathrm{g} / \mathrm{m}^{3}$ (median: $1.90 \mu \mathrm{g} / \mathrm{m}^{3}$ ) from tobacco-flavored ECs and $1.48 \mu \mathrm{g} / \mathrm{m}^{3}$ (median: $1.05 \mu \mathrm{g} / \mathrm{m}^{3}$ ) from mentholflavored ECs. There were no statistically significant differences in the mean concentrations of nicotine based on flavor or puffing times.

\section{Aerosol particles ( $\mathrm{PM}_{2.5}$, nanoparticles, and PNC)}

Particle mass and number concentrations generated from EC aerosols were identified in all tested ECs. The mean concentration of nanoparticles was significantly higher from tobacco-flavored ECs than from mentholflavored ECs $\left(1,942.8\right.$ vs $\left.762.1 \mathrm{ng} / \mathrm{m}^{3}, p=0.013\right)$. For menthol-flavored ECs, a significantly higher mass concentration of nanoparticles was produced by $2 \mathrm{puff} / \mathrm{min}$ than by $1 \mathrm{puff} / \mathrm{min}\left(1,029.0\right.$ vs $\left.495.3 \mathrm{ng} / \mathrm{m}^{3}, p<0.001\right)$. There was no significant difference in nanoparticle concentrations based on puffing time for the tobacco-flavored ECs. We found significant differences in the number concentration of nanoparticles based on flavor (menthol: 7,463.2 vs tobacco: $14,801.8$ particles $/ \mathrm{cm}^{3}, p=0.013$ ) and puffing time. The mean PNC was significantly higher from tobacco-flavored ECs than from menthol-flavored ECs $\left(19,635.3\right.$ vs $\left.10,329.3 / \mathrm{cm}^{3}, p=0.012\right)$. When stratified by puffing time, $2 \mathrm{puffs} / \mathrm{min}$ produced a significantly higher PNC than $1 \mathrm{puff} / \mathrm{min}$ for the menthol-flavored ECs $\left(12,790.0\right.$ vs $7,868.5$ particles $\left./ \mathrm{cm}^{3}, \mathrm{p}=0.024\right)$ and for the tobacco-flavored ECs $\left(23,232.0\right.$ vs $16,038.5$ particles $\left./ \mathrm{cm}^{3}\right)$. There was no significant difference in $\mathrm{PM}_{2.5}$ concentrations based on flavor or puffing time. When we adjusted for puffing time, tobacco flavoring increased the mass concentration of nanoparticles by $162 \%$ ( $95 \%$ CI, $124 \%$ to $206 \%$ ), the number concentration of nanoparticles by $101 \%$ ( $95 \% \mathrm{CI}, 85 \%$ to $119 \%$ ), and the PNC by $93 \%$ ( $95 \%$ $\mathrm{CI}, 72 \%$ to $117 \%$ ) in comparison to menthol flavoring (Fig. 2).

\section{Carbonyls}

The concentration of acetaldehyde was measured from menthol ECs at $1 \mathrm{puff} / \mathrm{min}$, but the other groups had concentrations below the method's detection limit. The mean concentration of acetone was $3.35 \mathrm{ppb}$ from tobacco ECs at 2 puffs/min, while the other groups had levels mostly below the method's detection limit.

\section{VOCs}

Of the 18 VOCs, ethanol, acetonitrile, isopropyl alcohol, benzene, and toluene had concentrations above the LOD. Toluene was only detected from tobacco ECs at 2 $\mathrm{puffs} / \mathrm{min}$.

\section{Trace elements}

Silicon (Si), Chlorine (Cl), Barium (Ba), and Indium (In) were detected depending on the flavor and puffing time, while other elements were below the method's detection limit. 


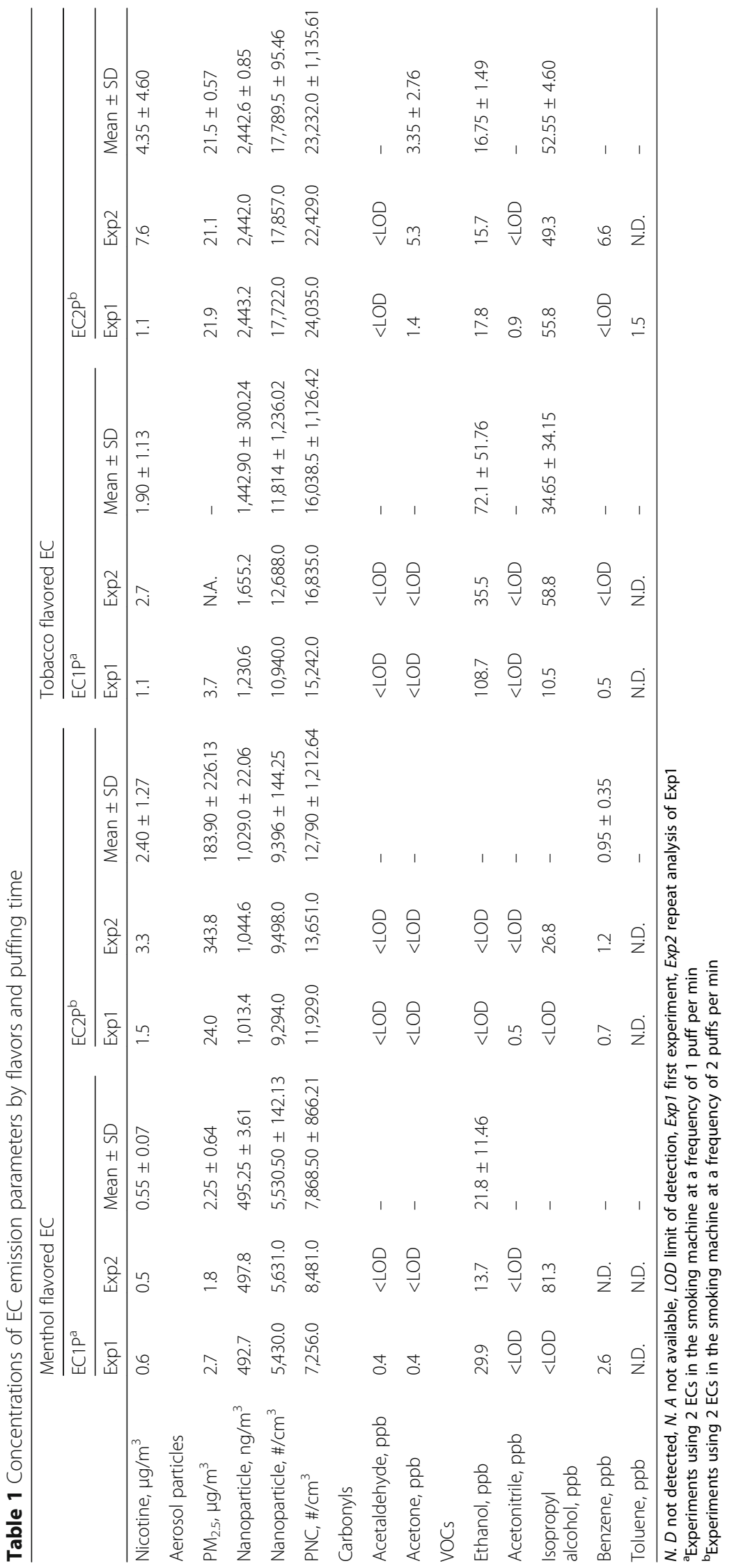




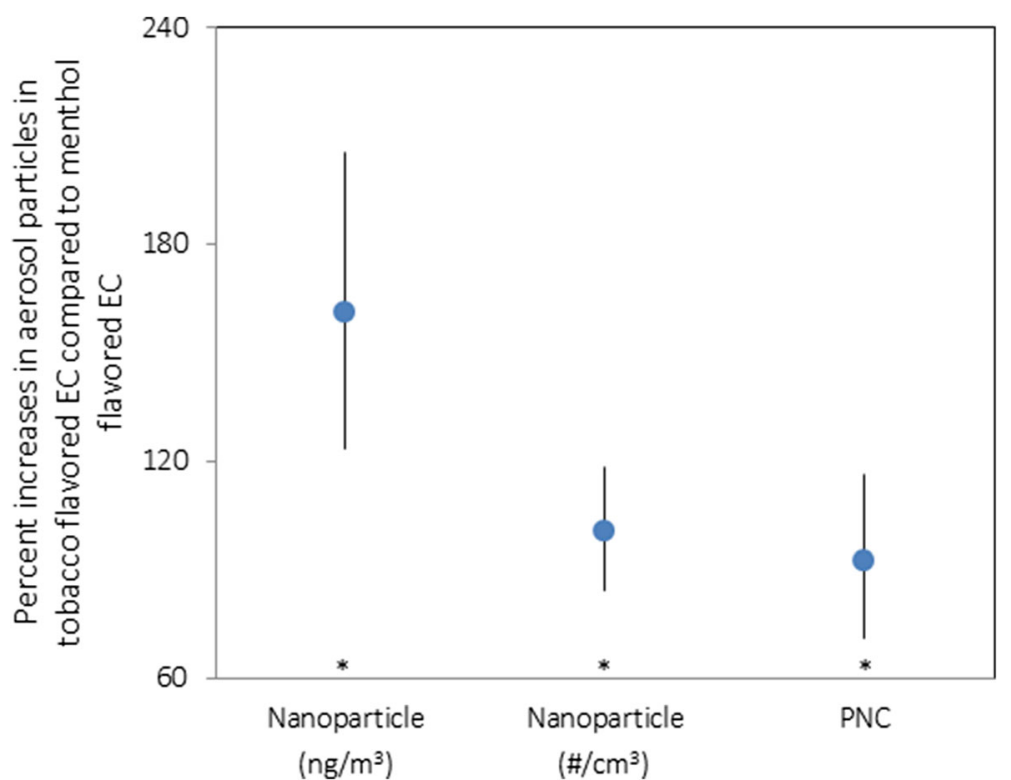

Fig. 2 Estimated percent increases and $95 \% \mathrm{Cls}$ in aerosol particles associated with type of flavor, adjusting for puffing time. Circle blue symbols indicate the effect estimate. ${ }^{*} p<0.001$

\section{Discussion}

Our findings suggest that nicotine, fine and nanoparticles, other toxic chemicals, and carcinogens are present in the emissions from the two dominant flavors of ECs sold in the U.S. In this study, acetaldehyde and benzene were identified at low levels. Tobacco-flavored ECs delivered higher mass and number concentrations of nanoparticles than menthol-flavored ECs.

Our results confirm findings from previous studies in which nicotine, aerosol particles, and other toxic chemicals were detected in EC emission $[5,16]$. Nicotine is a highly addictive substance found in cigarette smoke and other tobacco products including ECs. A study by $\mathrm{Fu}$ and colleagues in Spain [24] collected 30-min measurements of airborne nicotine as a marker of second-hand smoke (SHS) exposure in various settings including healthcare centers, bars, public administration offices, educational centers, and on public transport. The median concentration of airborne nicotine was $1.36 \mu \mathrm{g} / \mathrm{m}^{3}$ (range: 0.43 to $4.33 \mu \mathrm{g} / \mathrm{m}^{3}$ ), which is similar to the levels observed in this study (median: $1.30 \mu \mathrm{g} / \mathrm{m}^{3}$, range: 0.50 to $7.60 \mu \mathrm{g} / \mathrm{m}^{3}$ ). The mean concentration of nicotine generated from ECs in the present study $\left(2.3 \mu \mathrm{g} / \mathrm{m}^{3}\right)$ was somewhat lower than airborne nicotine levels measured for $1 \mathrm{~h}$ in indoor offices in the US (mean: $3.8 \mu \mathrm{g} / \mathrm{m}^{3}$ ) [12], but nicotine levels generated from tobacco-flavored ECs (mean: $3.13 \mu \mathrm{g} / \mathrm{m}^{3}$ ) in this study were similar. In a study by Baek and colleagues in Korea [13], mean concentrations of airborne nicotine measured for $2 \mathrm{~h}$ were $1.8 \mu \mathrm{g} / \mathrm{m}^{3}$ for home indoors,
$2.5 \mu \mathrm{g} / \mathrm{m}^{3}$ for offices indoors, and $4.8 \mu \mathrm{g} / \mathrm{m}^{3}$ for restaurants indoors. The nicotine concentrations in EC emissions in the present study were somewhat higher than home indoor concentrations (mean: $1.43 \mu \mathrm{g} / \mathrm{m}^{3}$ ) [14] and greater than outdoor concentrations measured for $30 \mathrm{~min}$ (median: $0.81 \mu \mathrm{g} / \mathrm{m}^{3}$ ) [15], implying that ECs deliver nicotine in doses that are comparable to secondhand exposure from conventional tobacco cigarettes.

In this study, the median concentration of $\mathrm{PM}_{2.5}$ was $21.1 \mu \mathrm{g} / \mathrm{m}^{3}$ (mean: $59.86 \mu \mathrm{g} / \mathrm{m}^{3}$ ), which is similar to the airborne concentrations in indoor and outdoor assessments of SHS exposure [15, 24] and passive exposure to EC emissions in a simulated café [25]. In this study, there was no significant difference in the concentration of $\mathrm{PM}_{2.5}$ based on flavor, but flavor affected $\mathrm{PM}_{2.5}$ levels in a prior study [26]. Previous studies reported that ECs deliver high levels of nanoparticles $[1,24,27,28]$, which can penetrate deep into the respiratory tract, reach the alveolar sacs $[29,30]$ and carry toxic chemicals into the blood stream. These toxic chemicals can then appear in various organs including the liver, kidney, heart and brain [31]. In the present study, nanoparticles were observed in all examined EC emissions. Our study indicates that menthol-flavored ECs produce fewer nanoparticles and lower PNCs than the tobacco-flavored ECs, which is consistent with previously published data [26]. In contrast, a previous study reported that flavors did not change the PNC levels [4]. Based on our results, the tobacco-flavored ECs generated more particles than menthol-flavored 
ECs. Given a previous report suggesting that particles emitted from ECs have different physical and chemical properties compared to particles in cigarette smoke [32] and that EC aerosols do not contain true particulate matter unlike combustible cigarette smoke [33], fine and ultrafine particles present in EC aerosols are not directly comparable with those in cigarette smoke.

In this study, small amounts of carbonyls and toxic VOCs were detected in EC aerosols. More importantly, carcinogens such as benzene and acetaldehyde were identified. Toluene was detected only in emissions from tobacco-flavored ECs at 2 puffs/min. Acetaldehyde, a major component in the gas phase of tobacco smoke, is of particular interest because of its carcinogenic and genotoxic effects [21]. Acute exposure to acetaldehyde results in irritation of the eyes, skin, and respiratory tract in humans [34]. Acetaldehyde induced DNA and chromosomal damage in human lymphocyte in vitro [35-37]. Our findings are consistent with those from previous studies in which trace amounts of acetaldehyde were detected in EC emissions [1, 5, 16, 25, 38]. Acetaldehyde was found in vapors exhaled in an $8 \mathrm{~m}^{3}$ test chamber by volunteer EC users [1]. Geiss and colleagues [16] reported carbonyls were below the method LOD in the air of a30 $\mathrm{m}^{3}$ chamberbut were detected when the carbonyls were determined from a gas sampling bag directly connected to the smoking machine. In a study by Goniewicz and colleagues [5], the content of acetaldehyde in emissions from EC cartridges ranged from 0.11 to $1.36 \mu \mathrm{g}$ per 15 puffs. In this study, acetaldehyde in EC emissions was mostly below the LOD, but was detected at $0.4 \mathrm{ppb}$ from menthol ECs at 1 puff/ min. Studies have reported that carbonyl levels generated from the first-generation (cigarette-like) EC devices, as used in our study, were lower than levels found in tobacco cigarette smoke [5, 38]. A recent study has reported that new-generation EC devices at high power produce high levels of aldehyde but only under 'dry puff' conditions, which deliver a strong unpleasant taste by overheating the liquid [39].

The presence of VOCs has been reported in EC emissions. Ten of 12 brands emitted detectable levels of toluene and $m, p$-xylene but not benzene [5]. None of these compounds were found in passive exposure to EC emissions [1]. Benzene was detected in EC emissions from volunteer EC users, but it was also found at the same level in background concentrations [25]. In a study by McAuley and colleagues [40], small amounts of benzene, toluene, ethylbenzene, and m,p-xylene were detected above LOD. In this study, five of the analyzed VOCs were detected: ethanol, acetonitrile, isopropyl alcohol, benzene, and toluene.
Benzene is a well-known hematotoxic carcinogen that can cause leukemia [22]. While carcinogens are found in trace amount in EC emissions, the effects of EC emission on cancer risk have not been reported.

Here, trace elements such as $\mathrm{Si}, \mathrm{Cl}, \mathrm{Ba}$, and In were found at trace levels while others were below LOD. Trace amounts of toxic metals such as $\mathrm{Cd}, \mathrm{Ni}$, and $\mathrm{Pb}$ were present in EC emissions in previous studies, but the same elements were also detected in blank samples $[5,25]$.

There is a need for caution in interpreting our findings. Exposure limits and standards recommended or set by agencies and organizations such as the Occupational Safety and Health Administration (OSHA), the National Institute for Occupational Safety (NIOSH), the American Conference of Governmental Industrial Hygienists (ACGIH), the U.S. Environmental Protection Agency (EPA), and the World Health Organization (WHO) have been established for the compounds that were detected in EC emissions [41-47] (Table 2). Although airborne levels of carbonyls and VOCs in EC emissions are considerably lower than the occupational standards and guidelines, there are no standards for the general public. The application of occupational exposure limits (OELs) in the workplace to non-occupational exposure in the general public may not be entirely applicable or appropriate for EC users because OELs are set for workers who are at a greater risk than the general population [48]. For $\mathrm{PM}_{2.5}$, about half of the samples in our study exceeded the annual mean of NAAQS and WHO guidelines. Thus, our findings should not be interpreted as "safe" or as "acceptable".

It is also important to be cautious about generalizing our results because our findings are limited to the small number of ECs tested and the conditions of testing. Another potential limitation is that the constituents delivered via machine-generated EC emissions may not reflect the emissions exhaled by an EC user, although nicotine levels generated by our smoking machine were found to be similar to those exhaled from EC users [49]. In addition, our results exhibited variation in the content of EC emissions in duplicate experiments. Previous studies have shown large variation in carbonyl concentrations among individual ECs from the same brand [50]. One possible factor to explain our experimental variation is that we used a different cartridge for the duplicate experiments. We suspect that this may contribute to the observed variation in constituent levels and to the range of particle size distribution within products. Alternatively, it is also possible that our simulation system may suffer from different conditioning following the sequence of the simulation. Additional studies 


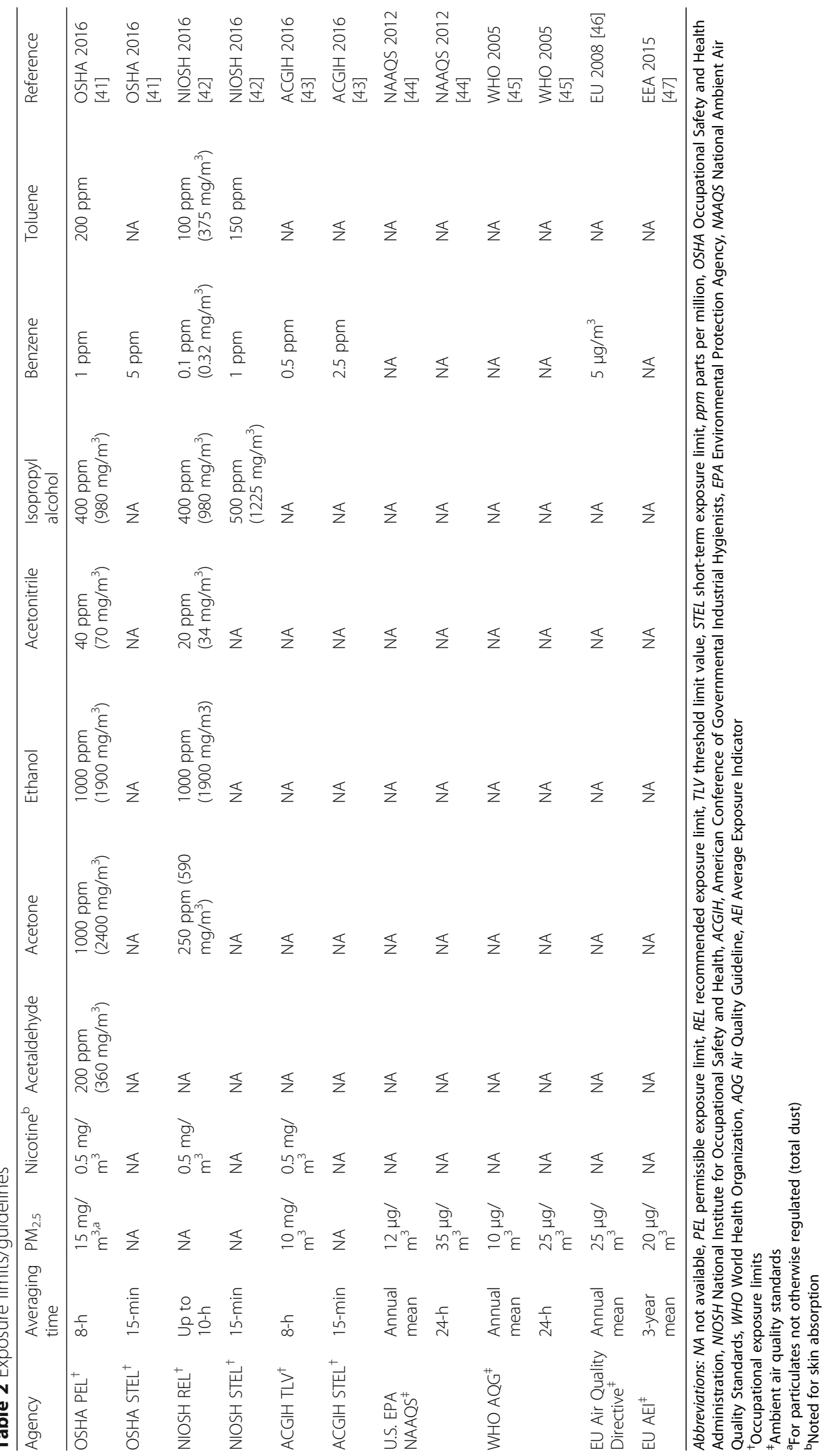


based on scientifically validated aerosol generation and chemical analysis methods are needed.

\section{Conclusions}

In summary, EC emissions contain measurable amounts of nicotine, fine and nanoparticles, and other toxic chemicals, implying that EC emissions are a new source of environmental pollution and should be investigated further.

\begin{abstract}
Abbreviations
ACGIH: American conference of governmental industrial hygienists; Cls: Confidence intervals; EC: Electronic cigarette; EPA: Environmental protection agency; IARC: International agency for research on cancer; LOD: Limit of detection; NIOSH: National Institute for Occupational Safety and Health; OSHA: Occupational Safety and Health Administration; $\mathrm{PM}_{2.5}$ : Particulate matter of aerodynamic diameter less than $2.5 \mu \mathrm{m}$; PNC: Particle number concentration; UFPs: Ultrafine particles, particulate matter of aerodynamic diameter less than $100 \mathrm{~nm}$; VOCs: Volatile organic compounds; WHO: World Health Organization
\end{abstract}

\section{Acknowledgement}

We would like to thank Joy Lawrence and Jack M. Wolfson for their assistance in the collection and analysis of the samples.

\section{Funding}

This publication was made possible by US EPA grant number RD-834798 and NIEHS grant number P30ES000002. Its contents are solely the responsibility of the grantee and do not necessarily represent the official views of the USEPA or the NIEHS. Further, USEPA and NIEHS do not endorse the purchase of any commercial products or services mentioned in the publication. The findings and conclusions in this report are those of the authors and do not necessarily represent the views of the National Institute for Occupational Safety and Health (NIOSH). Mention of any company or product does not constitute endorsement by NIOSH. In addition, citations to Web sites external to NIOSH do not constitute NIOSH endorsement of the sponsoring organizations or their programs or products. Furthermore, NIOSH is not responsible for the content of these Web sites.

\section{Availability of data and materials}

Please contact author for data requests.

\section{Authors' contributions}

DCC conceptualized and supervised the project, writing, and revision. RFL, YSS, and PK designed the exposure experiment setting, data collection, and contributed to writing and revision. MSL conceptualized and designed the project, statistical analysis, and wrote the manuscript. All authors read and approved the final manuscript.

\section{Competing interests}

The authors declare that they have no competing interests.

\section{Consent for publication}

Not applicable.

\section{Ethics approval and consent to participate}

Not applicable.

\section{Publisher's Note}

Springer Nature remains neutral with regard to jurisdictional claims in published maps and institutional affiliations.

\section{Author details}

'Environmental and Occupational Medicine and Epidemiology Program, Department of Environmental Health, Harvard T. H. Chan School of Public Health, 665 Huntington Ave, Building I Room 1401, Boston MA 02115, USA ${ }^{2}$ Centers for Disease Control and Prevention (CDC), National Institute for Occupational Safety and Health (NIOSH), Respiratory Health Division, Field Studies Branch, Morgantown, WW, USA. ${ }^{3}$ Research Division for Industry \&
Environment, Advanced Radiation Technology Institute, Korea Atomic Energy Research Institute, Daejeon, South Korea. ${ }^{4}$ Exposure, Epidemiology and Risk Program, Department of Environmental Health, Harvard T. H. Chan School of Public Health, Boston, MA, USA. ${ }^{5}$ Massachusetts General Hospital/Harvard Medical School, Boston, MA, USA.

Received: 27 October 2016 Accepted: 11 April 2017

Published online: 27 April 2017

\section{References}

1. Schripp T, Markewitz D, Uhde E, Salthammer T (2013) Does e-cigarette consumption cause passive vaping? Indoor Air 23(1):25-31

2. Cheng T (2014) Chemical evaluation of electronic cigarettes. Tob Control 23: ii11-ii17

3. Grana R, Benowitz N, Glantz SA (2014) E-cigarettes: a scientific review. Circulation 129(19):1972-1986

4. Fuoco FC, Buonanno G, Stabile L, Vigo P (2014) Influential parameters on particle concentration and size distribution in the mainstream of ecigarettes. Environ Pollut 184:523-529

5. Goniewicz ML, Knysak J, Gawron M, Kosmider L, Sobczak A, Kurek J et al (2014) Levels of selected carcinogens and toxicants in vapour from electronic cigarettes. Tob Control 23(2):133-139

6. Fernández E, Ballbè M, Sureda X, Fu M, Saltó E, Martínez-Sánchez JM (2015) Particulate matter from electronic cigarettes and conventional cigarettes: a systematic review and observational study. Curr Environ Health Rep 2(4):423-9

7. Pankow JF, Kim K, McWhirter K, Luo W, Escobedo JO, Strongin RM, Duell AK, Peyton DH (2017) Benzene formation in electronic cigarettes. PLoS One 12(3):e0173055

8. Williams M, Villarreal A, Bozhilov K, Lin S, Talbot P (2013) Metal and silicate particles including nanoparticles are present in electronic cigarette cartomizer fluid and aerosol. PloS one 8(3):e57987

9. Giovenco DP, Hammond D, Corey CG, Ambrose BK, Delnevo CD (2015) Ecigarette market trends in traditional U.S. retail channels, 2012-2013. Nicotine Tob Res 17(10):1279-1283

10. Farsalinos KE, Spyrou A, Tsimopoulou K, Stefopoulos C, Romagna G, Voudris $\checkmark$ (2014) Nicotine absorption from electronic cigarette use: comparison between first and new-generation devices. Sci Rep 4:4133

11. European Commission (2013) Revision of the tobacco products directivepress release (European parliament)., Available at: http://www.europarl. europa.eu/pdfs/news/expert/infopress/20131216IPR31001/ 20131216IPR31001_en.pdf

12. Turner S, Cyr L, Gross AJ (1992) The measurement of environmental tobacco-smoke in 585 office environments. Environ Int 18(1):19-28

13. Baek SO, Kim YS, Perry R (1997) Indoor air quality in homes, offices and restaurants in Korean urban areas - Indoor/outdoor relationships. Atmos Environ 31(4):529-544

14. Butz AM, Breysse P, Rand C, Curtin-Brosnan J, Eggleston P, Diette GB et al (2011) Household smoking behavior: effects on indoor air quality and health of urban children with asthma. Matern Child Health J 15(4):460-468

15. Sureda X, Martinez-Sanchez JM, Lopez MJ, Fu M, Aguero F, Salto E et al (2012) Secondhand smoke levels in public building main entrances: outdoor and indoor PM2.5 assessment. Tob Control 21(6):543-548

16. Geiss O, Bianchi I, Barahona F, Barrero-Moreno J (2015) Characterisation of mainstream and passive vapours emitted by selected electronic cigarettes Int J Hyg Environ Health 218(1):169-180

17. Morabia A, Amstislavski PN, Mirer FE, Amstislavski TM, Eisl H, Wolff MS et a (2009) Air pollution and activity during transportation by car, subway, and walking. Am J Prev Med 37(1):72-77

18. Zhu K, Zhang J, Lioy PJ (2007) Evaluation and comparison of continuous fine particulate matter monitors for measurement of ambient aerosols. J Air Waste Manag Assoc 57(12):1499-1506

19. Colton MD, MacNaughton P, Vallarino J, Kane J, Bennett-Fripp M, Spengler JD, Adamkiewicz G (2014) Indoor air quality in green vs conventional multifamily low-income housing. Environ Sci Technol 48:7833-7841

20. LeBouf RF, Stefaniak AB, Virji MA (2012) Validation of evacuated canisters for sampling volatile organic compounds in healthcare settings. J Environ Monit 14(3):977-983

21. IARC. IARC Monograph 71: re-evaluation of some organic chemicals, hydrazine and hydrogen peroxide. 1999. Available at: http://monographs. iarc.fr/ENG/Monographs/vol71/mono71.pdf. Accessed date 19 Oct 2016. 
22. IARC. IARC Monograph $100 \mathrm{~F}$ : Chemical Agents and Related Occupations, p. 249-294. 2012. Available at: http://monographs.iarc.fr/ENG/Monographs/ vol100F/mono100F.pdf. Accessed 19 Oct 2016.

23. Kang CM, Achilleos S, Lawrence J, Wolfson JM, Koutrakis P (2014) Inter-lab comparison of elemental analysis for low ambient urban $\mathrm{PM}_{2.5}$ levels. Environ Sci Tech 48:12150-12156

24. Fu M, Martinez-Sanchez JM, Galan I, Perez-Rios M, Sureda X, Lopez MJ et al (2013) Variability in the correlation between nicotine and PM2.5 as airborne markers of second-hand smoke exposure. Environ Res 127:49-55

25. Schober W, Szendrei K, Matzen W, Osiander-Fuchs H, Heitmann D, Schettgen T et al (2014) Use of electronic cigarettes (e-cigarettes) impairs indoor air quality and increases FeNO levels of e-cigarette consumers. Int J H Environ Health 217(6):628-637

26. Ji EH, Sun BB, Zhao TK, Shu S, Chang CH, Messadi D et al (2016) Characterization of electronic cigarette aerosol and its induction of oxidative stress response in oral keratinocytes. PloS one 11(5):e0154447

27. Mikheev VB, Brinkman MC, Granville CA, Gordon SM, Clark PI (2016) Realtime measurement of electronic cigarette aerosol size distribution and metals content analysis. Nicotine Tob Res 18(9):1895-902

28. Ingebrethsen BJ, Cole SK, Alderman SL (2012) Electronic cigarette aerosol particle size distribution measurements. Inhal Toxol 24(14):976-984

29. Bakand S, Hayes A, Dechsakulthorn F (2012) Nanoparticles: a review of particle toxicology following inhalation exposure. Inhal Toxicol 24(2):125-135

30. Oberdorster G, Oberdorster E, Oberdorster J (2005) Nanotoxicology: an emerging discipline evolving from studies of ultrafine particles. Environ Health Perspect 113(7):823-839

31. Terzano C, Di Stefano F, Conti V, Graziani E, Petroianni A (2010) Air pollution ultrafine particles: toxicity beyond the lung. Eur Rev Med Pharmacol Sci 14(10):809-821

32. Burstyn I (2014) Peering through the mist: systematic review of what the chemistry of contaminants in electronic cigarettes tells us about health risks. BMC Public Health 14:18

33. Farsalinos KE, Gillman IG, Hecht SS, Polosa R, Thornburg J. Analytical assessment of e-cigarettes. $1^{\text {st }}$ Edition. From contents to chemical and particle exposure profiles. Cambridge: Elsevier; 2016.

34. U.S. EPA. Health Assessment Document for Acetaldehyde. EPA/600/8-86 015A. Environmental Criteria and Assessment Office, Office of Health and Environmental Assessment, office of Research and Development, Research Triangle Park, NC. 1987.

35. Lambert B, He SM (1988) DNA and chromosome damage induced by acetaldehyde in human lymphocytes in vitro. Ann N Y Acad Sci 534:369-376

36. Singh NP, Khan A (1995) Acetaldehyde: genotoxicity and cytotoxicity in human lymphocytes. Mutat Res 337(1):9-17

37. Blasiak J, Trzeciak A, Malecka-Panas E, Drzewoski J, Wojewodzka M (2000) In vitro genotoxicity of ethanol and acetaldehyde in human lymphocytes and the gastrointestinal tract mucosa cells. Toxicol In Vitro 14(4):287-295

38. Bekki K, Uchiyama S, Ohta K, Inaba Y, Nakagome H, Kunugita N (2014) Carbonyl compounds generated from electronic cigarettes. Int J Environ Res Public Health 11(11):11192-11200

39. Farsalinos KE, Voudris V, Poulas K (2015) E-cigarettes generate high levels of aldehydes only in 'dry puff' conditions. Addiction 110(8):1352-1356

40. McAuley TR, Hopke PK, Zhao J, Babaian S (2012) Comparison of the effects of e-cigarette vapor and cigarette smoke on indoor air quality. Inhal Toxicol 24(12):850-857

41. OSHA. Air Contaminants. 29 CFR 1910.1000 [71 FR 16673, April 3, 2006]. 2016. Web site: https://www.osha.gov/dsg/annotated-pels/tablez-1.html, Accessed on 30 Jan 2012

42. NIOSH. NIOSH pocket guide to chemical hazards. Department of Health and Human Services. Centers for Disease Control and Prevention. Web site last updated on May 18, 2016. DHHS (NIOSH) Publication No. 2005-149. 2007. http://www.cdc.gov/niosh/docs/2005-149/pdfs/2005-149.pdf

43. ACGIH. Threshold Limit Values for Chemical Substances in the Work Environment. Adopted by $\mathrm{ACGIH}^{\oplus}$ with Intended Changes. 2016. store/ProductFormPublic/ search?action=1\&Product_categories_Checkboxes=2/store/ProductFormPublic/ search?action=1\&Product_categories_Checkboxes=2

44. US EPA. Fact Sheets and Additional information Regarding the 2012 Revision to the Particulate Matter $\left(\mathrm{PM}_{2.5}\right)$ National Ambient Air Quality Standards (NAAQS). https://www.epa.gov/pm-pollution/table-historicalparticulate-matter-pm-national-ambient-air-quality-standards-naaqs. Accessed 19 Apr 2017.
45. WHO. Air quality guidelines for particulate matter, ozone, nitrogen dioxide and sulfur dioxide - Global update 2005 - Summary of risk assessment. 2005. http://apps.who.int/iris/bitstream/10665/69477/1/WHO_SDE_PHE_OEH_06. 02_eng.pdf

46. EU. Directive 2008/50/EC of the European Parliament and of the Council of 21 May 2008 on ambient air quality and cleaner air for Europe (OJ L 152, 11.6.2008, p. 1-44). 2008. http://eur-lex.europa.eu/LexUriServ/LexUriServ. do?uri=OJ:L:2008:152:0001:0044:EN:PDF

47. European Environment Agency (EEA). Air quality in Europe - 2015 report. http://www.eea.europa.eu/publications/air-quality-in-europe-2015. Accessed 19 Apr 2017.

48. Castorina R, Woodruff TJ (2003) Assessment of potential risk levels associated with U.S. Environmental protection agency reference values. Environ Health Perspect 111(10):1318-1325

49. Czogala J, Goniewicz ML, Fidelus B, Zielinska-Danch W, Travers MJ, Sobczak A (2014) Secondhand exposure to vapors from electronic cigarettes. Nicotine Tob Res 16:655-662

50. Uchiyama S, Ohta K, Inaba Y, Kunugita N (2013) Determination of carbonyl compounds generated from the e-cigarette using coupled silica cartridges impregnated with hydroquinone and 2,4-dinitrophenylhydrazine, followed by high-performance liquid chromatography. Anal Sci 29(12):1219-1222

\section{Submit your next manuscript to BioMed Central and we will help you at every step:}

- We accept pre-submission inquiries

- Our selector tool helps you to find the most relevant journal

- We provide round the clock customer support

- Convenient online submission

- Thorough peer review

- Inclusion in PubMed and all major indexing services

- Maximum visibility for your research

Submit your manuscript at www.biomedcentral.com/submit
Biomed Central 